\title{
The Border of Reproductive Control: Undocumented Immigration as a Risk Factor for Unintended Pregnancy in Switzerland
}

\author{
Alejandra Casillas • Patrick Bodenmann • \\ Manuella Epiney $\cdot$ Laurent Gétaz · Olivier Irion • \\ Jean-Michel Gaspoz $\cdot$ Hans Wolff
}

Published online: 2 November 2013

(C) Springer Science+Business Media New York 2013

\begin{abstract}
Unintended pregnancies reflect an unmet need for family planning, and are part of health disparities. Using the only database to inquire about pregnancy intention among women in Switzerland, this study examined the relationship between immigrant documentation and unintended pregnancy (UP). Among pregnant women presenting to a Swiss hospital, we compared pregnancy intention between documented and undocumented women. We used logistic regression to examine whether undocumented status was associated with UP after adjusting for other significant predictors. Undocumented women had more unintended pregnancies ( 75.2 vs. $20.6 \%, p=0.00$ ). Undocumented status was associated with UP after adjustment (OR 6.23, $95 \%$ CI 1.83-21.2), as was a history of psychological problems (OR 4.09, $95 \%$ CI 1.32-12.7). Contraception non-use was notably associated with lower odds of UP (OR 0.01, $95 \%$ CI 0.004-0.04). Undocumented status was significantly associated with UP, even after adjusting for well-recognized risk factors. This
\end{abstract}

A. Casillas · L. Gétaz · J.-M. Gaspoz · H. Wolff

Penitentiary Medicine Service, Geneva University Hospitals, Geneva, Switzerland
A. Casillas ( $\square)$
Service de Médecine de Premier Recours, 9 étage, aile Jura, bureau 7A-9-731.3, Hôpitaux Universitaires de Genève, Rue Gabrielle-Perret-Gentil 4, 1211 Geneva 14, Switzerland e-mail: Doctorale05@gmail.com; alejandra.casillas@hcuge.ch
P. Bodenmann
Policlinique Médicale Universitaire, CHUV, Lausanne
University Hospital, Lausanne, Switzerland
M. Epiney · O. Irion
Department of Gynecology and Obstetrics, Geneva University
Hospitals, Geneva, Switzerland

highlights the tremendous risk of undocumented status on UP among women in Switzerland.

Keywords Unintended pregnancy · Women's health · Immigrant health · Undocumented immigrants $\cdot$ Health disparities

\section{Introduction}

An unintended pregnancy (UP) is a pregnancy that is mistimed, unplanned, or unwanted at conception [1, 2]. Representing the unmet need for family planning, it is a public health issue at the core of women's fertility and their reproductive freedom [3].

Unintended pregnancy results in significant societal costs and poor maternal and child health outcomes [4-8]. International calls for the development of indicators that measure the "unmet need for fertility regulation" have advanced the issue as a matter of sexual health rights [9]. Given the consequences that families face from unplanned births and unsafe abortions, preventing UP is an international health priority $[9,10]$. Since 2010 , the universal right to effective family planning forms part of the 2015 United Nations Millennium Development Goals, in line with the International Conference on Population and Development in Cairo, and the World Health Organization [9, 11].

Importantly, unintended pregnancies also form part of the widening gap of health disparities affecting vulnerable women like undocumented immigrants [12-16]. Today, it is estimated that up to $3.8 \%$ of the Swiss population is not documented, a proportion that is similar to that of the United States [17]. Despite being a small country, Switzerland has become a common transit and destination point for migration from all over the world; contributing factors 
being the poor global market, Switzerland's central location in Europe, and its multiple official languages. However, the country's strict visa and asylum policies make undocumented immigration a reality for most migrants. An estimated 8,000-12,000 undocumented migrants live and work daily in the city of Geneva alone [18, 19]. Although these populations may purchase health insurance regardless of status, they are often limited by the demanding premiums of Swiss plans [12]. Furthermore, existing health burdens are magnified by language barriers, cultural stigma, precarious social support networks, lack of awareness about available health resources, and continued fear of immigration authorities, all of which limit undocumented immigrants' ability to effectively access care in this setting [14, 16, 20-22]. Notably, it has already been demonstrated that undocumented women in Geneva have particularly low rates of primary care and poor knowledge of birth control [12, 13, 23], likely putting them at risk for unintended pregnancies.

Following in the direction of these international health guides, and health disparities agendas in the industrialized world that explicitly address increasing rates of UP $[3,4,8$, 24], Geneva health institutions have begun to focus on risk factors for unintended pregnancies, particularly among the waves of new immigrants. Our specific aim was to examine the effect of undocumented status on UP among women presenting at a Swiss public hospital in Geneva. This is a novel analysis, and the first of its kind in Switzerland, as no other database exists that asks about UP among women residing in Switzerland.

\section{Methods}

\section{Participants, Data Collection}

This secondary data analysis uses cross-sectional data collected from pregnant women who presented to the women's University Hospital in Geneva from February 2005 to October 2006. The data is part of a broader study on women's health [13] supported by the "Migrant Friendly Hospitals" project in the Swiss federal office of public health, which promotes research towards the development of Swiss healthcare centers that are skillful in cross-cultural care [25].

Only women with plans to reside in Geneva (with a Geneva contact address) were included in the study. As part of the broader study protocol, case managers and social workers contacted/visited with questionable cases, to insure (to the best of their knowledge) that tourist patients were excluded from recruitment. Women who were unable to provide informed consent or who decided to have a voluntary termination of pregnancy (TOP) were also excluded from the pregnancy study. Participants completed a questionnaire in face-to-face interviews with midwives (fluent in Spanish and French) during the initial pregnancy consultation and/or follow-up. All participants were provided written informed consent prior to joining the study. Ethics approval for the study was obtained through the University of Geneva Institutional Review Board (IRB).

\section{Measures}

The dependent variable of interest in this study was UP. To capture intention of the current pregnancy, women were asked whether their pregnancy had been "planned" or "accidental"; "accidental" was defined as "unintended" for these analyses. The main independent variable was documentation status. All women (including Swiss citizens) were asked whether they had legal permission to reside in Switzerland, to which they could reply "yes" or "no." Women who responded "no" were counted as undocumented in Switzerland. We examined the effect of undocumented status on UP, and the effect of other predictors: socio-demographics, family interaction, health services utilization, violence exposure and psychological trauma, in multivariate models.

Potential covariates were selected based on previous study findings regarding UP and significant predictors, particularly among vulnerable populations. This list was pared down to 17 variables: using variables with over $75 \%$ data present for both undocumented and documented women, and accounting for power, and sensitivity tests (colinearity and correlation with UP). Selected socio-demographic covariates were age, marital status, whether the woman was employed and whether her living quarters were comprised of more than one room (a Geneva-specific marker for socioeconomic status). Family interaction or social support factors included whether the respondent had a stable relationship with the man responsible for the current pregnancy, if she had a family member in Geneva, and whether she had children.

Health service utilization variables included if she ever had a cervical cancer screen, whether she took medications, and whether she was using contraception (including nonhormonal methods like condom and diaphragm, and insecure methods like rhythm and retraction) at conception. Women who did not use contraception were classified as "nonuser" versus any type of contraception. Other health service covariates were: history of any voluntary TOP and knowledge of emergency contraception. Drug use addressed using tobacco and other substance use. For violence, women were asked if they had been exposed to any form of violence (physical, verbal, psychological or sexual) in their lifetime. We also included respondents' reported psychological trauma: past treatment for a psychological disorder and if currently under any treatment for a psychological disorder. 


\section{Statistical Analysis}

We obtained descriptive statistics of the study sample of 394 women who completed the questionnaire, in relation to all our variables of interest. Using Chi square exact tests, we compared the proportion of UP between documented and undocumented women. We used simple logistic regression to examine all variables' association with UP. We then used multivariate logistic regression to examine whether undocumented status was associated with UP after stepwise adjusting for the described variable groups. We also performed stratified analyses to examine significance of these factors with UP, among undocumented and documented women alone. We present odds ratios with $95 \%$ confidence intervals (CI) of the unadjusted and adjusted estimates. Significant results are at the $p \leq 0.05$ level.

Out of the 394 women whose data were included in these analyses, $76 \%$ had complete responses for the study variables included in the final model. The following variables had the highest missing data rates: stable relation with newborn's father $(10.2 \%)$, single room apartment $(10.4 \%)$, family in Geneva $(10.7 \%)$, has child $(10.7 \%)$ and knowledge of emergency contraception (10.2\%). Although the quantity of these missing variables was higher among the undocumented women, overall patterns of missing variables were randomly distributed among the observations, thus we proceeded with list-wise deletion of observations with missing data. The analysis retained 298 observations for all regression models. We used Stata version 12 for our analyses.

\section{Results}

Out of 409 women who were invited to participate, 394 accepted $(96 \%)$. Of these women, 161 were undocumented immigrants $(40.9 \%)$. Nearly all $(84 \%)$ of the undocumented women in our study sample were from Latin America, (Asia-6.2 \%, Europe-5.6\%, Africa-4.3\%) and they were all uninsured. Undocumented women had a higher proportion of UP (75.2 vs. $20.6 \%, p=0.00$ ) (Table 1).

Undocumented women had a lower mean age of 29.4, versus 31.1 for the documented women. In terms of sociodemographics, there were stark differences: $72.5 \%$ of documented women were married while only $20.5 \%$ of
Table 1 Characteristics of undocumented pregnant women versus pregnant women with legal residency status at the Geneva University Hospital

* Comparison of proportions: Chi square; test for means: independent samples $t$ test

\begin{tabular}{|c|c|c|c|}
\hline & $\begin{array}{l}\text { Undocumented } \\
(\mathrm{n}=161)\end{array}$ & $\begin{array}{l}\text { Documented } \\
(\mathrm{n}=233)\end{array}$ & $p$ value* \\
\hline Unintended pregnancy & $75.2 \%$ & $20.6 \%$ & 0.00 \\
\hline \multicolumn{4}{|l|}{ Socio-demographics } \\
\hline Mean age in years & 29.4 (SD 5.8) & $31.1(\mathrm{SD} 4.8)$ & 0.002 \\
\hline Married (ref. non-married) & $20.5 \%$ & $72.5 \%$ & 0.00 \\
\hline Not working (ref. employed) & $0.0 \%$ & $18.0 \%$ & 0.00 \\
\hline Apartment: one room only (ref. $>1$ room) & $62.5 \%$ & $18.0 \%$ & 0.00 \\
\hline \multicolumn{4}{|l|}{ Family interaction and support } \\
\hline $\begin{array}{l}\text { Stable relationship with father of the newborn: spouse/ } \\
\text { partner/fiancé (ref. occas./none/other) }\end{array}$ & $76.2 \%$ & $97.4 \%$ & 0.00 \\
\hline No family member in Geneva (ref. family in Geneva) & $53.3 \%$ & $32.3 \%$ & 0.00 \\
\hline Have children (ref. no children) & $23.7 \%$ & $52.4 \%$ & 0.00 \\
\hline \multicolumn{4}{|l|}{ Health services utilization } \\
\hline Never had a pap test (ref. has had a pap test) & $13.0 \%$ & $0.0 \%$ & 0.00 \\
\hline Takes medications (ref. no medications) & $45.6 \%$ & $88.0 \%$ & 0.00 \\
\hline No contraception when got pregnant (ref. user) & $57.4 \%$ & $83.2 \%$ & 0.00 \\
\hline Any voluntary TOP (ref. no history) & $27.0 \%$ & $24.0 \%$ & 0.51 \\
\hline $\begin{array}{l}\text { No knowledge of emergency contraception as possibility } \\
\text { (ref. has knowledge) }\end{array}$ & $61.2 \%$ & $9.0 \%$ & 0.00 \\
\hline \multicolumn{4}{|l|}{ Drug use } \\
\hline Never used tobacco (ref. has used tobacco) & $70.3 \%$ & $48.1 \%$ & 0.001 \\
\hline Other substance use (ref. no substance use) & $3.4 \%$ & $17.4 \%$ & 0.00 \\
\hline \multicolumn{4}{|l|}{ Violence } \\
\hline Lifetime violence exposure (ref. never had violence) & $30.7 \%$ & $26.0 \%$ & 0.32 \\
\hline \multicolumn{4}{|l|}{ Psychological trauma } \\
\hline Past treatment for psychological disorder (ref. none) & $13.8 \%$ & $16.9 \%$ & 0.46 \\
\hline Current treatment for psychological disorder (ref. none) & $4.6 \%$ & $3.1 \%$ & 0.45 \\
\hline
\end{tabular}


undocumented respondents had a spouse. All of the undocumented women were employed and $82 \%$ of the documented worked; $62.5 \%$ of undocumented women lived in a singlequarters apartment versus $18 \%$ of documented women. In terms of family interaction, notably $53.3 \%$ of undocumented respondents had no family member in Geneva compared to $32.3 \%$ of documented women.

Examining health services, all of the documented women had received a cervical cancer screen at least once in their lifetime, compared to $13 \%$ of undocumented women who never had a pap smear. While $57.4 \%$ of undocumented women did not use contraception when they became pregnant, $83.2 \%$ of documented women were not using contraception. However, on follow-up questioning on "reason for no-contraception" among the non-users, $48.5 \%$ said they wanted a baby (a little later) and $5.6 \%$ said they wanted a baby at the present moment. Therefore, over $50 \%$ of the women not using contraception did so purposefully because they desired pregnancy - this pattern was more prevalent among the documented women with 177 out of 193 documented contraception non-users (92\%) expressing a pregnancy desire in follow-up questions. In comparison, 34 out of 85 undocumented contraception non-users (40\%) expressed this desire.

Notably, $61.2 \%$ of undocumented women had no knowledge of emergency contraception as a possibility while only $9 \%$ of documented women lacked this knowledge. With regards to drug use, more documented women used tobacco in their lifetime, and other substances. There were no significant differences with regards to violence or psychological trauma.

Table 2 shows that undocumented status was associated with UP even after adjustment (OR 6.23, $95 \%$ CI 1.83-21.20). Having a stable relationship with the father was the only family interaction variable that remained significant (OR 0.10, $95 \%$ CI 0.02-0.60). For health services utilization factors, contraception non-use was protective against UP, and remained significant after adjustment (OR 0.01, 95 \% CI 0.004-0.04).

Given that different modes of contraception (with different efficacy and effectiveness) were grouped, we checked the distribution of UP among each type of contraception, to see if contraception type made any difference
Table 2 Logistic regression models of unintended pregnancy among all women

\begin{tabular}{|c|c|c|}
\hline Predictor (reference) & $\begin{array}{l}\text { Unadjusted } \\
\text { OR, } 95 \% \mathrm{CI}\end{array}$ & $\begin{array}{l}\text { Adjusted } \\
\text { OR, } 95 \% \text { CI }\end{array}$ \\
\hline \multicolumn{3}{|l|}{ Primary predictor } \\
\hline Undocumented (documented) & $11.7,7.16-19.0^{\dagger}$ & $6.23,1.83-21.2 * *$ \\
\hline \multicolumn{3}{|l|}{ Socio-demographics } \\
\hline Age & $0.95,0.92-0.99 *$ & $0.97,0.89-1.05$ \\
\hline Married (non-married) & $0.17,0.11-0.27^{\dagger}$ & $0.62,0.25-1.59$ \\
\hline Not working (employed) & $0.24,0.11-0.57^{\dagger}$ & $1.19,0.30-4.66$ \\
\hline Apartment: one room only ( $>1$ room) & $4.87,3.00-7.90^{\dagger}$ & $1.77,0.66-4.71$ \\
\hline \multicolumn{3}{|l|}{ Family interaction and support } \\
\hline $\begin{array}{l}\text { Stable relationship with father of the newborn: spouse/partner/ } \\
\text { fiancé (occas./none/other) }\end{array}$ & $0.07,0.02-0.21^{\dagger}$ & $0.10,0.02-0.60 *$ \\
\hline No family member in Geneva (family in Geneva) & $2.13,1.36-3.34^{\dagger}$ & $1.03,0.43-2.47$ \\
\hline Have children (no children) & $0.43,0.27-0.68^{\dagger}$ & $0.961,0.36-2.56$ \\
\hline \multicolumn{3}{|l|}{ Health services utilization } \\
\hline Never had a pap test (has had a pap test) & $13.3,3.02-58.3^{\dagger}$ & $4.93,0.39-61.8$ \\
\hline Takes medications (no medications) & $0.28,0.18-0.45^{\dagger}$ & $0.44,0.16-1.21$ \\
\hline No contraception when got pregnant (user) & $0.04,0.02-0.08^{\dagger}$ & $0.01,0.004-0.04^{\dagger}$ \\
\hline Any voluntary TOP (no history) & $0.99,0.62-1.58$ & $0.35,0.12-0.99 *$ \\
\hline $\begin{array}{l}\text { No knowledge of emergency contraception as possibility } \\
\text { (has knowledge) }\end{array}$ & $4.41,2.67-7.29^{\dagger}$ & $0.64,0.21-1.97$ \\
\hline \multicolumn{3}{|l|}{ Drug use } \\
\hline Never used tobacco (has used tobacco) & $1.18,0.782-1.78$ & $1.41,0.55-3.64$ \\
\hline Other substance use (no substance use) & $0.74,0.39-1.42$ & $1.14,0.35-3.75$ \\
\hline \multicolumn{3}{|l|}{ Violence } \\
\hline Lifetime violence exposure (never had violence) & $1.79,1.13-2.18^{*}$ & $1.31,0.52-3.33$ \\
\hline \multicolumn{3}{|l|}{ Psychological trauma } \\
\hline Past treatment for psychological disorder (none) & $1.55,0.87-2.77$ & $4.09,1.32-12.7 *$ \\
\hline Current treatment for psychological disorder (none) & $1.07,0.33-3.44$ & $0.03,0.002-0.46^{*}$ \\
\hline
\end{tabular}


Table 3 Logistic regression models of unintended pregnancy in stratified analyses

\begin{tabular}{|c|c|c|c|c|}
\hline \multirow[t]{2}{*}{ Predictor (reference) } & \multicolumn{2}{|c|}{ Undocumented alone } & \multicolumn{2}{|l|}{ Documented alone } \\
\hline & $\begin{array}{l}\text { Unadjusted } \\
\text { OR, } 95 \% \text { CI }\end{array}$ & $\begin{array}{l}\text { Adjusted } \\
\text { OR, } 95 \% \mathrm{CI}\end{array}$ & $\begin{array}{l}\text { Unadjusted } \\
\text { OR, } 95 \% \text { CI }\end{array}$ & $\begin{array}{l}\text { Adjusted } \\
\text { OR, } 95 \% \mathrm{CI}\end{array}$ \\
\hline \multicolumn{5}{|l|}{ Socio-demographics } \\
\hline Age & $1.01,0.95-1.10$ & $0.95,0.80-1.20$ & $0.95,0.90-1.02$ & $0.98,0.90-1.10$ \\
\hline Married (non-married) & $0.29,0.10-0.60 * *$ & $0.15,0.004-6.00$ & $0.44,0.20-0.90^{*}$ & $0.77,0.30-2.40$ \\
\hline Not working (employed) & - & - & $0.73,0.30-1.80$ & $0.79,0.20-3.30$ \\
\hline Apartment: one room only ( $>1$ room) & $0.93,0.40-2.40$ & $29.1,0.50-1,789$ & $4.03,1.95-8.30^{\dagger}$ & $1.86,0.50-7.00$ \\
\hline \multicolumn{5}{|l|}{ Family interaction and support } \\
\hline $\begin{array}{l}\text { Stable relationship with father of the newborn: } \\
\text { spouse/partner/fiancé (occas./none/other) }\end{array}$ & $0.10,0.01-0.80 *$ & $0.011,0.00-6.50$ & $0.25,0.05-1.30$ & $0.12,0.01-2.00$ \\
\hline No family member in Geneva (family in Geneva) & $1.86,0.70-4.60$ & $0.33,0.01-7.50$ & $1.50,0.80-2.90$ & $0.912,0.31-3.00$ \\
\hline Have children (no children) & $0.31,0.10-0.80^{*}$ & $0.03,0.00-2.03$ & $1.10,0.60-2.10$ & $1.84,0.60-6.20$ \\
\hline \multicolumn{5}{|l|}{ Health services utilization } \\
\hline Never had a pap test (has had a pap test) & $2.99,0.70-13.60$ & $66.3,0.03-1,500$ & - & - \\
\hline Takes medications (no meds) & $0.79,0.40-1.70$ & $0.01,0.00-0.38^{*}$ & $0.75,0.30-1.90$ & $1.72,0.30-9.50$ \\
\hline No contraception when got pregnant (user) & $0.12,0.04-0.40^{\dagger}$ & $0.00,0.00-0.04^{* *}$ & $0.02,0.01-0.05^{\dagger}$ & $0.01,0.002-0.04^{\dagger}$ \\
\hline Any voluntary TOP (no history) & $0.53,0.20-1.20$ & $0.004,0.00-0.26^{* *}$ & $1.23,0.60-2.50$ & $0.70,0.20-2.30$ \\
\hline $\begin{array}{l}\text { No knowledge of emergency contraception as } \\
\text { possibility (has knowledge) }\end{array}$ & $0.90,0.40-2.10$ & $0.50,0.03-10.2$ & $2.10,0.80-5.50$ & $0.37,0.10-2.40$ \\
\hline \multicolumn{5}{|l|}{ Drug use } \\
\hline Never used tobacco (has used tobacco) & $0.92,0.40-2.00$ & $0.70,0.03-14.5$ & $0.65,0.30-1.20$ & $1.24,0.40-3.96$ \\
\hline Other substance use (no substance use) & $0.80,0.09-7.40$ & $17.8,0.20-19.4$ & $0.53,0.20-1.10$ & $1.15,0.30-4.50$ \\
\hline \multicolumn{5}{|l|}{ Violence } \\
\hline Lifetime violence exposure (never had violence) & $1.47,0.60-3.60$ & $0.96,0.04-23.4$ & $2.27,1.20-4.50^{*}$ & $1.18,0.40-3.60$ \\
\hline \multicolumn{5}{|l|}{ Psychological trauma } \\
\hline Past treatment for psychological disorder (none) & $2.51,0.50-11.70$ & $1.55,0.05-44.4$ & $2.26,1.10-4.80^{*}$ & $5.60,1.90-19.2^{* *}$ \\
\hline Under treatment for psychological disorder (none) & $1.30,0.10-12.10$ & $0.00,0.00-0.10^{*}$ & $0.64,0.08-5.50$ & $0.04,0.002-1.00$ \\
\hline
\end{tabular}

-: number too small within group to compare

$* p \leq 0.05 ; * * p \leq 0.01 ;{ }^{\dagger} p \leq 0.001$

in the comparisons. The rates of UP among all women, according to contraception mode were as follows: no contraception $(\mathrm{n}=287): 25 \%$; retraction $(\mathrm{n}=5): 80 \%$; calendar $(\mathrm{n}=13)$ : $85 \%$; emergency contraception pill $(\mathrm{n}=2)$ : $100 \%$; oral contraceptive pill $(\mathrm{n}=31): 93 \%$; condom $(\mathrm{n}=41): 88 \%$; patch $(\mathrm{n}=3): 100 \%$; nuvaring $(\mathrm{n}=1): 0 \%$; depoprovera $(\mathrm{n}=5): 100 \%$; diaphragm $(\mathrm{n}=1): 100 \%$. The percentages of UP ranged from 83 to $100 \%$ for all forms of contraception types among undocumented women and 50-100\% for all contraception types among documented women. Thus, among all women and in stratified analysis, using any contraception mode indeed increased the odds of UP, versus nonusers (except for the $\mathrm{n}=1$ in relation to the nuvaring). Insecure contraception was defined as condom, retraction or calendar. When examining users of contraception $(n=100)$, there was no difference in insecure contraception usage between documented $(53.8 \%)$ and undocumented women $(60.3 \%)$. Furthermore, when comparing those who used insecure contraception versus those did not use insecure contraception, there was also no significant difference in UP rates-among all women: 92.9 versus $86.2 \%$; undocumented alone: 91.9 versus $95.8 \%$; documented women alone: 76.2 versus $88.9 \%$.

Having a history of voluntary TOP decreased odds for UP after adjustment (OR 0.35, 95 \% CI 0.12-0.99). Current treatment for a psychological disorder was protective (OR 0.03, $95 \%$ CI 0.002-0.46), while past treatment actually increased odds for UP (OR 4.09, $95 \%$ CI 1.32-12.7).

\section{Stratified Analyses}

To fully examine the effect of these covariates on UP, and given the potential for interaction between documentation status and covariates, we also performed stratified analyses (Table 3). Among the undocumented women, the following variables significantly decreased the odds of UP after 
adjustment: contraception non-use (OR $0.00,95 \%$ CI 0.00-0.04), medication use (OR $0.01,95 \%$ CI $0.0-0.38$ ), history of voluntary TOP (OR $0.004,95 \%$ CI $0.00-0.26$ ) and being under any current treatment for psychological disorder (OR 0.00, $95 \%$ CI 0.00-0.10).

Among the documented women, after adjustment, contraception non-use remained significant (OR 0.01, $95 \%$ CI 0.002-0.04). Past history of psychological treatment increased the odds of UP (OR 5.60, $95 \%$ CI 1.90-19.2).

\section{Discussion}

Undocumented status increased the odds of UP despite controlling for known risk factors that disproportionately affected the undocumented women in this study. Similar associations with UP have been found among recently migrated women in the United States (though lack of documentation is difficult to explicitly examine) [20]. The increased odds for UP can be partially explained by the social burdens that limit immigrants' ability, especially undocumented immigrants, to access effective contraception services [16, 26]. Nevertheless more work remains in explaining the complex relationships connecting the numerous predisposing risks that place undocumented women at risk for UP.

Past treatment for a psychological disorder increased the odds for an UP, also calling attention to this group. The association with psychological issues is well documented, with UP being linked to depression, intimate partner violence, household trauma, a history of abuse and a history of non-consensual sexual debut at age 15 or younger [20, $27-$ 29]. Interestingly, women currently under any treatment for psychological disorder had decreased odds for UP, possibly reflecting an ongoing access to health services, which could predispose to an access to family planning [30-32]. Indeed, we found that factors linked to health utilization were protective. This conclusion was reinforced when we examined undocumented women alone in stratified analyses and found that taking medications, a history of voluntary TOP, and currently receiving treatment for a psychological disorder, all decreased the odds of UP.

As expected, having a stable relationship with the father of the newborn decreased odds for UP among all women, although this finding was not statistically significant in stratified analyses. However, studies of women's reproductive practices have repeatedly shown that partners play an important role in family planning choices, such as utilization of contraception, attitudes surrounding pregnancy intentions, and decision-making regarding pregnancy options [33]. This also coincides with literature showing that unintended births are more common among single women and women not living with their partners [20]. In one study among the urban poor, partner status was the strongest predictor of UP, increasing the risk 2.5-fold for single women [34]. Notably though, women who are poor, have a lower education level, and who are undocumented are also less likely to have domestic stability, plan reproductive choices effectively with their partner, or be married-prominent factors which all affect risk for UP [2, 14].

We found that contraception non-use decreased the odds of UP among all women and in stratified analyses. Using any contraception mode increased the odds of UP, versus nonusers. While this was somewhat unexpected, a 2012 Guttmacher brief did show that American women who used contraception inconsistently or incorrectly accounted for $43 \%$ of all unintended pregnancies [1]. It is estimated that in the United States and France, $50 \%$ and $65 \%$ of women, respectively, report this as the reason for an UP [26, 35].

Unfortunately, we did not have information about the frequency or effectiveness of contraception use for women using contraception [32, 36, 37]. Use of ineffective contraceptive methods like condom and non-hormonal approaches, insecure contraception such as calendar and retraction methods, and/or frank misuse of contraception is linked not only to socio-demographic factors that affect knowledge and reproductive self-efficacy, but also to ambivalent attitudes about pregnancy planning [35, 38]. Although in this study we did not find a difference in UP between users of insecure contraception (condom, calendar, retraction) and secure contraception, the high rates of insecure contraception among all women who were contraception users (documented: $53.8 \%$, undocumented: $60.3 \%$ ) distributes focus to the need for the teaching of effective and correctly utilized methods in these populations, and for delving into why women prefer certain contraceptive approaches. In Switzerland, insecure methods do not cost much while more reliable methods are expensive and not provided for free (as in other European countries). In fact, most insurance companies in Switzerland do not even cover the prescription costs for contraception. In the study's clinic setting, women are eligible for free or reduced full-spectrum contraception services, depending on a financial sliding scale. Despite considerable progress, there is much to learn about contraceptive use [2].

We also propose a more technical explanation for the unexpected contraception-use finding. As stated in the results, on follow-up questioning among the non-users about why they did not use contraception, over $50 \%$ of the women not using contraception expressed some desire for pregnancy-this pattern was more prevalent among the documented women. Admittedly, this added information confounds the interpretation of the contraception variable, but adds further credence to our discussion above about pregnancy attitudes affecting contraceptive use and choices. 
There are of course limitations to this study. Because this is a cross-sectional study, causation cannot be assessed. As well, it is difficult to present our results in light of any population-based indices for UP in Switzerland, as there are none. Estimates for Swiss unintended pregnancies are based on surveys from neighboring European countries, with Western Europe at $32 \%$ (compared to $55 \%$ worldwide, and $42 \%$ in more developed countries) [39].

Despite a small sample size, we had a high participation rate $(96 \%)$ for the study. Two variables that we would have liked to account for include insurance and race/ethnicity. However, insurance and race/ethnicity (Latina) were co-linear with documentation status, making it difficult to distinguish the effects of these variables from the primary predictor.

As this was a secondary data analysis, our variable selection was limited to the availability of information that had already been collected. For example, data was not originally collected from women who intended to have abortions, and thus these cases were not included in our analyses. Another example is the description of UP used in this study. Pregnancy unintendedness is not an easily definable concept, and its exact meaning has been extensively reviewed and critiqued in methodological and sociological literature over the years [2]. The National Survey of Family Growth (NSFG) in the United States states that there is "a spectrum of intendedness, including ambivalence, and defines UP to include mistimed (time frame varying between studies), unplanned, or unwanted pregnancy" $[2,40]$. The original survey asked women whether their pregnancy had been "planned" or "accidental." We took "accidental" to mean "unintended" for these present analyses: our definition of UP was simplistic in this scope.

Although these results are based on 2005-2006 data, there is no other Swiss dataset that has asked about UP thereafter. Finally, since survey data was collected by faceto-face interviews, women may have responded differently given a social desirability bias or a stigma regarding UP. Yet despite the data limitations, our findings demonstrate that even in a small, well-controlled, and wealthy country like Switzerland, undocumented women continue to bear a significant risk for UP.

\section{New Contribution to the Literature}

This analysis is important and unique as it is the only study that inquires about UP among women in Switzerland, and one of the few studies that directly links UP to immigrant documentation status. Undocumented status was significantly associated with UP, even after adjusting for other significant and well-recognized risk factors. These findings highlight the tremendous risk of undocumented status on UP. The high rates of insecure contraception observed among all women, and the association between contraception use and
UP, also distributes focus to the need for the teaching of effective contraceptive methods. Public health systems in countries caring for incoming immigrants must make strides to ensure that all patients are counseled about family planning at any and every health visit (contraception options, preferences, and correct use of methods)-for the sake of diminishing the disparities that limit the reproductive freedom of women.

\section{References}

1. Guttmacher. Facts on unintended pregnancy in the United States. 2012; Available from: http://www.guttmacher.org/pubs/FBUnintended-Pregnancy-US.html, cited 2013 March 12, 2013.

2. Santelli J, Rochat R, Hatfield-Timajchy K, Gilbert BC, Curtis K, Cabral R, et al. The measurement and meaning of unintended pregnancy. Perspect Sex Reprod Health. 2003;35(2):94-101.

3. CDC. Unintended pregnancy prevention. Centers for disease control; 2012; CDC Reproductive Health website]. Available from: http:// www.cdc.gov/reproductivehealth/unintendedpregnancy/, cited 2013 Jan 25, 2013.

4. Institute of Medicine, Executive Summary. In: Brown S, Eisenberg L, editors. The best intentions: unintended pregnancy and the well-being of children and families. 1995.

5. Shapiro-Mendoza C, Selwyn BJ, Smith DP, Sanderson M. Parental pregnancy intention and early childhood stunting: findings from Bolivia. Int J Epidemiol. 2005;34(2):387-96.

6. Trussell J. The cost of unintended pregnancy in the United States. Contraception. 2007;75(3):168-70.

7. Trussell J, Wynn LL. Reducing unintended pregnancy in the United States. Contraception. 2008;77(1):1-5.

8. HealthyPeople.gov. Family Planning. 2012; Healthy People 2020 Topics and Objectives in Family Planning]. Available from: http:// www.healthypeople.gov/2020/topicsobjectives2020/overview. aspx?topicid=13, cited 2013 Jan 25, 2013.

9. Dixon-Mueller R, Germain A. Fertility regulation and reproductive health in the millennium development goals: the search for a perfect indicator. Am J Public Health. 2007;97(1):45-51.

10. Glasier A, Gülmezoglu AM, Schmid GP, Garcia-Moreno C, VanLook P. Sexual and reproductive health: a matter of life and death. Lancet. 2006;368(9547):1595-607.

11. United Nations. Keeping the promise: united to achieve the Millennium Development Goals. 2010; General Assembly for update of UN Millennium Development Goals]. Available from: http://www.un.org/en/mdg/summit2010/pdf/outcome_document N1051260.pdf, cited 2013 August 13, 2013.

12. Wolff H, Stalder H, Epiney M, Walder A, Irion O, Morabia A. Health care and illegality: a survey of undocumented pregnant immigrants in Geneva. Soc Sci Med. 2005;60(9):2149-54.

13. Wolff H, Epiney M, Lourenco AP, Costanza MC, DelieutrazMarchand J, Andreoli N, et al. Undocumented migrants lack access to pregnancy care and prevention. BMC Public Health. 2008;8:93.

14. Reed MM, Westfall JM, Bublitz C, Battaglia C, Fickenscher A. Birth outcomes in Colorado's undocumented immigrant population. BMC Public Health. 2005;5:100.

15. Leeman L. Medical barriers to effective contraception. Obstet Gynecol Clin N Am. 2007;34(1):19-29.

16. Kullgren J. Restrictions on undocumented immigrants access to health services: the public health implications of welfare reform. Am J Public Health. 2003;93(10):1630-3. 
17. Karl-Trummer U, Novak-Zezula S, Metzler B. Access to healthcare for undocumented migrants in the EU: a first landscape of NowHereland. Eurohealth. 2010;16(1):13-6.

18. Wolff H, Janssens P, Bodemann P, Meynard A, Delhumeau C, Rochat $\mathrm{T}$, et al. Undocumented migrants in Switzerland: geographical origin versus legal status as risk factor for tuberculosis. J Immigr Minor Health. 2010;12(1):18-23.

19. Longchamp C, Aeborsold M, Rousselot B, Ratelband-Pally S. Sans-papier en Suisse: c'est la marché de l'emploi qui est déterminant, non pas la politique d'asile. Rapport final sur mandat de l'office fédéral des migrations. Bern: GFS; 2005.

20. Christensen AL, Perry DF, Le HN, Ahmed S. Correlates of unintended birth among low-income Hispanic immigrants at high risk for depression. J Immigr Minor Health. 2011;13(3):478-86.

21. Christensen AL, Stuart EA, Perry DF, Le HN. Unintended pregnancy and perinatal depression trajectories in low-income, high-risk Hispanic immigrants. Prev Sci. 2011;12(3):289-99.

22. Rodriguez MI, Angus L, Elman E, Darney PD, Caughey AB. Financial effect of instituting Deficit Reduction Act documentation requirements in family planning clinics in Oregon. Contraception. 2011;83(6):537-41.

23. Wolff H, Lourenco A, Bodenmann P, Epiney M, Uny M, Andreoli $\mathrm{N}$, et al. Chlamydia trachomatis prevalence in undocumented migrants undergoing voluntary termination of pregnancy: a prospective cohort study. BMC Public Health. 2008;8:391.

24. U S. Medical Eligibility Criteria for Contraceptive Use, 2010. MMWR Recomm Rep. 59(RR-4):1-86.

25. MFH. Migrant Friendly Hospitals, Federal Office of Public Health. 2013; Available from: http://www.bag.admin.ch/themen/gesundheits politik/07685/12522/13674/index.html?lang=en, cited 2013 August 20, 2013.

26. Rasch V, Knudsen LB, Gammeltoft T, Christensen JT, Erenbjerg $\mathrm{M}$, Christensen JJ, et al. Contraceptive attitudes and contraceptive failure among women requesting induced abortion in Denmark. Hum Reprod. 2007;22(5):1320-6.

27. Miller E, Decker MR, McCauley HL, Tancredi DJ, Levenson RR, Waldman J, et al. Pregnancy coercion, intimate partner violence and unintended pregnancy. Contraception. 2010;81(4):316-22.
28. Magnusson BM, Masho SW, Lapane KL. Adolescent and sexual history factors influencing reproductive control among women aged 18-44. Sex Health. 2011;8(1):95-101.

29. Dietz PM, Spitz AM, Anda RF, Williamson DF, McMahon PM, Santelli JS, et al. Unintended pregnancy among adult women exposed to abuse or household dysfunction during their childhood. JAMA. 1999;282(14):1359-64.

30. Curtis C, Huber D, Moss-Knight T. Postabortion family planning: addressing the cycle of repeat unintended pregnancy and abortion. Int Perspect Sex Reprod Health. 2010;36(1):44-8.

31. Lee JK, Parisi SM, Akers AY, Borrero S, Schwarz EB. The impact of contraceptive counseling in primary care on contraceptive use. J Gen Intern Med. 2011;26(7):731-6.

32. Finer LB, Zolna MR. Unintended pregnancy in the United States: incidence and disparities. Contraception. 2011;84(5):478-85.

33. Jackson E, Karasz A, Gold M. Family formation in the inner city: low-income men's perception of their role in unplanned conception and pregnancy prevention. J Health Care Poor Underserved. 2011;22(1):71-82.

34. Besculides M, Laraque F. Unintended pregnancy among the urban poor. J Urban Health. 2004;81(3):340-8.

35. Black KI, Gupta S, Rassi A, Kubba A. Why do women experience untimed pregnancies? A review of contraceptive failure rates. Best Pract Res Clin Obstet Gynaecol. 2010;24:443-55.

36. Bajos N, Leridon H, Goulard H, Oustry P, Job-Spira N. Contraception: from accessibility to efficiency. Hum Reprod. 2003; 18(5):994-9.

37. Frost JJ. The state of hormonal contraception today: overview of unintended pregnancy. Am J Obstet Gynecol. 2011;205(4 Suppl): S1-3.

38. Phares TM, Cui Y, Baldwin S. Effective birth control use among women at risk for unintended pregnancy in Los Angeles, California. Womens Health Issues. 2012;22(4):351-8.

39. Singh S, Sedgh G, Hussain R. Unintended pregnancy: worldwide levels, trends, and outcomes. Stud Fam Plann. 2010;41(4):241-8.

40. Levi A, Dau KQ. Meeting the national health goal to reduce unintended pregnancy. J Obstet Gynecol Neonatal Nurs. 2011; 40(6):775-81. 